\title{
Mortality and cancer morbidity in workers from an aluminium smelter with prebaked carbon anodes - part III: mortality from circulatory and respiratory diseases
}

\author{
Alf Rønneberg
}

\begin{abstract}
Objective-To investigate associations between exposure to pot emissions (fluorides, sulphur dioxide) and mortality from chronic obstructive lung disease, coal tar pitch volatiles and mortality from diseases related to atherosclerosis, and carbon monoxide and mortality from ischaemic heart disease.
\end{abstract}

Methods-Mortality between 1962 to 1991 was investigated in a cohort of 1085 men hired by a Norwegian aluminium smelter between 1922 and 1975. Associations between cumulative exposure and mortality were investigated through SMR analysis based on national mortality rates; temporal relations were explored by considering exposures only within specific time windows. Circulatory mortality was also investigated by Poisson regression analysis.

Results-There were 501 deaths $v$ 471.3 expected in the cohort. The excess was confined to short term workers and did not seem to be associated with exposures in the smelter. Analysis of mortality among the 661 men with at least three years employment showed associations between cumulative exposure to tar 40 years before observation and atherosclerotic mortality $(P=0.03)$, and between exposure to pot emissions 20-39 years before observation and mortality from chronic obstructive lung disease $(P=0 \cdot 06)$. No association was found between exposure to carbon monoxide and mortality from ischaemic heart disease, but cerebrovascular mortality was associated with exposure to pot emissions $(\mathbf{P}=\mathbf{0 \cdot 0 2})$. Results for atherosclerotic and cerebrovascular diseases were confirmed through Poisson regression analysis.

Conclusions-The data support previous findings of increased mortality from ischaemic heart disease in workers exposed to tar, and some support is also provided for earlier reports of increased respiratory mortality in potroom workers.

(Occup Environ Med 1995;52:255-261)

Keywords: polycyclic aromatic hydrocarbons; fluorides; carbon monoxide
Studies of mortality among aluminium smelter workers have shown lower mortality than expected from cardiovascular disease and conflicting results for respiratory mortality. ${ }^{1-3}$ Still, morbidity studies have provided evidence of chronic airways obstruction in aluminium workers exposed to emissions from the electrolytic pots, ${ }^{4}$ and an association between potroom work and ischaemic heart disease has been reported from one casecontrol study. ${ }^{5}$

I investigated mortality in a cohort of workers from a Norwegian aluminium smelter that operated from 1914 to 1975 . The study has been based on an assessment of exposure to coal tar pitch volatiles (tar), asbestos, heat stress, magnetic fields, and pot emissions (fluorides, sulphur dioxide, carbon monoxide) described in a separate paper. ${ }^{6}$ These data have also been used in a study of the cohort's cancer morbidity between 1953 and $1991 .^{7}$

Of the assessed exposures, carbon monoxide ${ }^{8}$ and $\operatorname{tar}^{9-11}$ have been associated with increased mortality from ischaemic heart disease in epidemiological studies of workers in other industries. The coal tar pitch volatiles encountered in the workroom atmosphere of aluminium smelters contain polycyclic aromatic hydrocarbons $(\mathrm{PAH}) \mathrm{s}$, some of which have been shown to stimulate atherosclerosis in experimental animals. ${ }^{12} 13$ Atherosclerosis is a characteristic lesion in ischaemic heart disease, peripheral arteriosclerosis, and most cases of sudden death. ${ }^{14}$

The objective of this study was to investigate certain associations between specific exposures and mortality-namely: pot emissions (fluorides, sulphur dioxide) and mortality from chronic obstructive lung disease; coal tar pitch volatiles and mortality from diseases related to atherosclerosis; pot emissions (carbon monoxide) and mortality from ischaemic heart disease and sudden death.

\section{Material and methods}

The investigation was designed as a retrospective cohort study of mortality between 1962 and 1991. During this period cause specific mortalities were available for the general population of Norway, and for all deaths the Central Bureau of Statistics had revised and coded the underlying cause according to the current revision of the International Classification of Diseases (ICD) from the medical death certificates and necropsy reports. ${ }^{15}$ 
Table 1 ICD codes grouped for analysis of specific causes of death

\begin{tabular}{llll}
\hline & $I C D-7(-1967)$ & $I C D-8(1968-85)$ & $I C D-9(1986-)$ \\
\hline Diseases related to atherosclerosis: & & & \\
$\quad$ Ischaemic heart disease & 420,422 & $410-414$ & $410-414$ \\
$\quad$ Peripheral arteriosclerosis & 450,455 & $440,444-445$ & 440,444 \\
$\quad$ Sudden death & 782,795 & 782,795 & 798 \\
Chronic obstructive lung disease: & & & 491 \\
Chronic bronchitis & 502 & 491 & 492 \\
Emphysema & 527 & 492 & 493 \\
Asthma & 241 & 493 & 496 \\
Chronic airway obstruction & - & - & \\
\hline
\end{tabular}

Formation of the study cohort has been described in detail in the cancer morbidity study. ${ }^{7}$ It was defined as all men hired in 1922 or later and employed for at least six months continuously. Of the 1209 men who satisfied this definition, 76 had died or emigrated before 1962, and vital status at the end of follow up could not be ascertained for 48 men through the Central Bureau of Statistics or interviews with former employees. This left 1085 men in the final cohort.

Each cohort member was examined for the event of death from 1 January 1962 or the time of hire if later until 31 December 1991 or the time of death or emigration if before this date. The underlying cause of death (3 digit ICD code) was obtained from the Central Bureau of Statistics with the personal identification number. No further revision of the cause of death was carried out.

The observation period spanned the 7 th, 8 th, and 9th revision of the ICD. Table 1 shows that the diseases of interest were combined in groups sharing a major pathogenic event and broad enough to show reasonable continuity across all three revisions. The category of atherosclerotic diseases included all deaths from ischaemic heart disease, peripheral arteriosclerosis, and sudden death, whereas chronic obstructive lung disease included all deaths from chronic bronchitis, emphysema, chronic airways obstruction, and asthma.

ANALYSIS OF STANDARDISED MORTALITY RATIO The cohort's mortality experience was investigated by comparing the observed number of deaths with the expected number calculated from age specific national mortalities by five year age groups for each year under observation. The standardised mortality ratio (SMR) was calculated as the ratio between the observed and expected number, and the $95 \%$ confidence interval $(95 \% \mathrm{CI})$ was calculated from the Poisson distribution for the observed number.

The intensity of exposure to coal tar pitch volatiles and pot emissions (fluorides, sulphur dioxide, carbon monoxide) had been assessed on a semiquantitative scale from zero to 1.00 for all jobs in the smelter. ${ }^{6}$ Dose-response relations between specific exposures and causes of death were investigated with cumulative exposure as a surrogate for dose. This was calculated in intensity-years as the prod- uct of exposure intensity and duration summed for all jobs held at the smelter.

Duration of employment and cumulative exposure were treated as time related variables with the values calculated for each person-year under observation, and one person was allowed to contribute to more than one stratum in each analysis. All unexposed person-years were assigned to one stratum, and the exposed person-years were divided into one low and one high stratum, each of which included an equal amount of person-time.

As in the cancer morbidity study, ${ }^{7}$ the temporal relation between exposure and mortality was explored by restricting exposure to specific time windows, and only exposures received within the window were considered to be aetiologically relevant. In the absence of evidence of the duration of the induction and latency periods, cumulative exposure was calculated within the time windows $0-19,20-39$, or $\geqslant 40$ years before observation. In the analysis of each time window, the unexposed stratum was defined as the person-years contributed by men employed in unexposed work at some time within the window. This prevented the presence of large age differences between the strata, as person-years were excluded if they were contributed by men who were too young or too old to be employed within the time window.

The choice of cumulative exposure as a surrogate for dose could be inappropriate in the case of pot emissions and ischaemic heart disease, as it has been proposed that the cardiovascular effects of carbon monoxide may be acute and reversible. ${ }^{16}$ This association was therefore also investigated by comparison of those employed in exposed and unexposed work at the smelter at the time of observation.

Each association was tested for trend with the Poisson trend statistic (two sided), ${ }^{17}$ and a result was regarded as significant if the $P$ value was less than 0.05 .

\section{POISSON REGRESSION ANALYSIS}

A potential source of bias in the stratified analysis is that SMRs may be incomparable across exposure groups that may result if the relative risk differs with age or period. Associations between cumulative exposure to tar and pot emissions and mortality from diseases related to atherosclerosis were therefore investigated by Poisson regression analysis ${ }^{18}$ that included the variables age, period, exposure to coal tar pitch volatiles, and exposure to pot emissions in the multiplicative model. The regression models were fitted by maximum likelihood estimation, and the importance of each variable was assessed by the likelihood ratio statistic. ${ }^{19}$ The associations were also tested for trend with a score test. ${ }^{20}$ Due to results obtained in the SMR analysis, mortality from cerebrovascular diseases was also included in the regression analysis.

Both the stratified SMR analysis and Poisson regression modelling were performed with the program package "epicure". ${ }^{21}$ 
Table 2 Observed (Obs) number of deaths, and SMRs with 95\% CIs among 1085 male aluminium smelter workers in 1962-91, by cumulative employment

\begin{tabular}{|c|c|c|c|c|}
\hline \multirow{3}{*}{$\begin{array}{l}\text { Cause of death } \\
\text { ICD-9 codes }\end{array}$} & \multicolumn{4}{|c|}{ Cumulative employment } \\
\hline & \multicolumn{2}{|c|}{$<3 y$} & \multicolumn{2}{|c|}{$\geqslant 3 y$} \\
\hline & $\overline{O b s}$ & $\operatorname{SMR}(95 \% C I)$ & Obs & $\operatorname{SMR}(95 \% C I)$ \\
\hline All causes & 183 & $1.29(1.10-1.48)$ & 318 & $0.97(0.86-1.07)$ \\
\hline Cancer $(140-208)$ & 54 & $1.83(1 \cdot 37-2 \cdot 39)$ & 64 & $0.94(0.72-1.20)$ \\
\hline Senile psychoses $(290)$ & 2 & $6.06(0.73-21.9)$ & 1 & $1.09(0.03-6.06)$ \\
\hline Hypertensive disease (401-5) & 3 & $1.70(0.35-4.98)$ & 8 & $1.92(0.83-3.78)$ \\
\hline Ischaemic heart disease $(410-4)$ & 46 & $1.00(0.73-1.33)$ & 94 & $0.88(0.71-1.07)$ \\
\hline Cerebrovascular disease $(430-8)$ & 11 & $0.80(0.40-1.43)$ & 36 & $1.01(0.72-1.43)$ \\
\hline Peripheral arteriosclerosis $(440,444)$ & 4 & $3.08(0.84-7.88)$ & 9 & $2 \cdot 61(1 \cdot 19-4.95)$ \\
\hline Pneumonia $(480-6)$ & 2 & $0.40(0.05-1.46)$ & 7 & $0.52(0.21-1.06)$ \\
\hline Chronic bronchitis (491) & 3 & $2.04(0.42-5.96)$ & 5 & $1.37(0.44-3.19)$ \\
\hline Emphysema (492) & 4 & $5 \cdot 48(1 \cdot 49-14 \cdot 0)$ & 3 & $1.69(0.35-4.95)$ \\
\hline Asthma (493) & 4 & $3.60(0.98-9 \cdot 23)$ & 1 & $0.39(0.01-2 \cdot 18)$ \\
\hline Other respiratory diseases $\star$ & 0 & $0.00(0.00-3.38)$ & 7 & $2.57(1.03-5 \cdot 30)$ \\
\hline Peptic ulcer $(531-4)$ & 3 & $3.66(0 \cdot 75-10 \cdot 7)$ & 2 & $1.04(0 \cdot 13-3 \cdot 74)$ \\
\hline Liver cirrhosis (571) & 0 & $0.00(0.00-3.42)$ & 1 & $0.48(0.01-2.67)$ \\
\hline Chronic nephritis (582) & 0 & $0.00(0.00-6.47)$ & 2 & $1.63(0.20-5.87)$ \\
\hline Sudden death (798) & 6 & $1.26(0.46-2 \cdot 75)$ & 10 & $0.93(0.45-1.72)$ \\
\hline Violent death $(800-999)$ & 14 & $1.50(0.82-2.52)$ & 18 & $1.11(0.66-1.75)$ \\
\hline All other causes & 27 & $1 \cdot 17(0 \cdot 77-1 \cdot 70)$ & 50 & $0.92(0.69-1.22)$ \\
\hline
\end{tabular}

^Five cases of chronic airways obstruction (496), two cases of pneumoconiosis (502).

\section{Results}

The cohort contributed 24996 person-years of observation. The cause of death was known for all men, except for two workers with less than three years employment. There were 501 deaths, compared with an expected number of $471 \cdot 29$. Table 2 shows the mortality in the cohort by cumulative employment in the smelter. Increased total mortality was found in men with less than three years employment (SMR $=1 \cdot 29, \mathrm{P}<0.01)$, due to excess deaths from cancer, emphysema, chronic bronchitis, asthma, peripheral arteriosclerosis, peptic ulcer, violent death, and senile psychoses.

In the group with at least three years employment total mortality was as expected (SMR $=0.97$ ), but excess deaths were found from peripheral arteriosclerosis, hypertensive disease, and other respiratory diseases, which included five deaths coded as chronic airways obstruction after its introduction in 1986 and two deaths from pneumoconiosis.

As the short term workers showed a different mortality pattern from that of the remaining cohort members, the two subcohorts were analysed separately.

Table 3 shows results from the SMR analysis of the associations that had been defined originally as of interest in the 661 men with at least three years' total employment. This group contributed 15418 person-years, and their mean age at hire was 27 years and the mean period from first employment to the end of follow up was 42 years.

A weak, positive association was found between cumulative exposure to tar and mortality from diseases related to atherosclerosis $(P=0 \cdot 19)$, but this association became significant when exposure was restricted to 40 years or more before observation $(P=0.03)$. Men exposed to tar in this time window showed excess deaths from both peripheral arteriosclerosis (SMR $=7 \cdot 69$, four deaths), sudden death ( $S M R=2.54$, three deaths), and ischaemic heart disease $(\mathrm{SMR}=1 \cdot 23,17$ deaths), and trend analysis showed a positive

Table 3 SMRs for selected clauses in 1962-91 among 661 aluminium smelter workers with at least three years' employment, by cumulative exposure to coal tar pitch volatiles and pot emissions

\begin{tabular}{|c|c|c|c|c|c|c|}
\hline \multirow[b]{3}{*}{$\begin{array}{l}\text { Exposure } \\
\text { cause of death }\end{array}$} & \multirow{3}{*}{$\begin{array}{l}\text { Time window } \\
\text { for exposure } \\
\text { before } \\
\text { observation (y) }\end{array}$} & \multicolumn{4}{|c|}{ Cumulative exposure (intensity-y) } & \multirow[b]{3}{*}{$\begin{array}{l}\text { P value } \\
\text { for trend }\end{array}$} \\
\hline & & \multicolumn{2}{|l|}{ Zero } & \multirow[b]{2}{*}{$\begin{array}{l}\text { Low } \\
\text { SMR (n) }\end{array}$} & \multirow[b]{2}{*}{$\begin{array}{l}\text { High } \\
\text { SMR (n) }\end{array}$} & \\
\hline & & $\begin{array}{l}\text { All } \\
S M R(n)\end{array}$ & $\begin{array}{l}\text { Employed } \\
\text { SMR }(n)\end{array}$ & & & \\
\hline \multirow[b]{2}{*}{$\begin{array}{l}\text { Ischaemic heart disease } \\
\text { Sudden death } \\
\text { Peripheral arteriosclerosis } \\
\text { Sum, atherosclerotic diseases }\end{array}$} & \multirow[b]{2}{*}{$\begin{array}{l}\text { All } \\
\text { All } \\
\text { All } \\
\text { All } \\
0-19 \\
20-39 \\
40+\end{array}$} & \multicolumn{4}{|c|}{ Coal tar pitch volatiles } & \multirow[b]{2}{*}{$\begin{array}{l}0.52 \\
0.06 \\
0.54 \\
0.19 \\
0.21 \dagger \\
0.47 \dagger \\
0.03 \dagger\end{array}$} \\
\hline & & $\begin{array}{l}0 \\
0 \cdot 84(60) \\
0 \cdot 70(5) \\
2 \cdot 12(5) \\
0 \cdot 86(70) \\
0 \cdot 88(90) \\
0 \cdot 92(85) \\
0 \cdot 84(89)\end{array}$ & $\begin{array}{l}0 \\
- \\
- \\
\overline{0} \\
0.80(46) \\
0.90(64) \\
0.93(47)\end{array}$ & $\begin{array}{l}<3 \\
0.94(14) \\
0.00(1.5) \\
4.76(2) \\
0.95(16) \\
1.47(14) \\
0.80(12) \\
1.40(11)\end{array}$ & $\begin{array}{l}\geqslant 3 \\
0.98(20) \\
2.43(5) \\
3.03(2) \\
1.16(27) \\
1.00(9) \\
1.17(16) \\
1.71(13)\end{array}$ & \\
\hline & & \multicolumn{4}{|c|}{ Pot emissions } & \\
\hline $\begin{array}{l}\text { Ischaemic heart disease } \\
\text { Sudden death } \\
\text { Chronic obstructive lung disease }\end{array}$ & $\begin{array}{l}\text { All } \\
\text { All } \\
\text { All } \\
0-19 \\
20-39 \\
40+\end{array}$ & $\begin{array}{l}0 \\
1.12(35) \\
0.33(1) \\
0.82(2) \\
1.47(9) \\
0.93(4) \\
1.40(7)\end{array}$ & $\begin{array}{l}0 \\
\overline{-} \\
\overline{0} \\
0 \cdot 75(2) \\
0.72(2) \\
0.60(1)\end{array}$ & $\begin{array}{l}<4.3 \\
0.82(26) \\
1.89(6) \\
2.38(6) \\
2.86(5) \\
1.78(4) \\
1.89(4)\end{array}$ & $\begin{array}{l}\geqslant 4 \cdot 3 \\
0 \cdot 75(33) \\
0.67(3) \\
1.69(6) \\
0.00(0 \cdot 7) \\
3.02(6) \\
2 \cdot 14(3)\end{array}$ & $\begin{array}{l}0 \cdot 10 \\
0 \cdot 79 \\
0 \cdot 48 \\
0 \cdot 69 \dagger \\
0 \cdot 06 \dagger \\
0 \cdot 27 \dagger\end{array}$ \\
\hline
\end{tabular}

$\star$ Employed in unexposed work at some time during time window. †The unexposed employed category $v$ low cumulative exposure $v$ high cumulative exposure. Expected number in italics if $\mathrm{SMR}=0.00$. 
Table 4 Standardised mortality ratios (SMRs) for cerebrovascular diseases from 1962-91 among 664 aluminium smelter workers with at least three years' employment, by cumulative exposure to coal tar pitch volatiles and pot emissions

\begin{tabular}{|c|c|c|c|c|c|}
\hline \multirow{3}{*}{$\begin{array}{l}\text { Time window } \\
\text { for exposure } \\
\text { to observation } \\
\text { (y) }\end{array}$} & \multicolumn{4}{|c|}{ Cumulative exposure (intensity-y) } & \multirow[b]{3}{*}{$\begin{array}{l}P \text { value } \\
\text { for trend }\end{array}$} \\
\hline & \multicolumn{2}{|l|}{ Zero } & \multirow[b]{2}{*}{$\begin{array}{l}\text { Low } \\
\text { SMR (n) }\end{array}$} & \multirow[b]{2}{*}{$\begin{array}{l}\text { High } \\
S M R(n)\end{array}$} & \\
\hline & $\begin{array}{l}\text { All } \\
\text { SMR (n) }\end{array}$ & $\begin{array}{l}\text { Employed * } \\
S M R(n)\end{array}$ & & & \\
\hline \multirow{3}{*}{$\begin{array}{l}\text { All } \\
0-19 \\
20-39 \\
40+\end{array}$} & \multicolumn{4}{|c|}{ Coal tar pitch volatiles } & \\
\hline & $\begin{array}{l}0 \\
1.02(24) \\
1.18(35) \\
1.02(27) \\
0.94(28)\end{array}$ & $\begin{array}{l}0 \\
0.97(15) \\
1.06(21) \\
1.37(22)\end{array}$ & $\begin{array}{l}<3 \\
1.10(5) \\
0.36(1) \\
0.93(4) \\
1.79(4)\end{array}$ & $\begin{array}{l}\geqslant 3 \\
1.06(7) \\
0.00(2.4) \\
1.29(5) \\
1.47(4)\end{array}$ & $\begin{array}{l}0.89 \\
0.08 \dagger \\
0.79 \dagger \\
0.79 \dagger\end{array}$ \\
\hline & \multicolumn{4}{|c|}{ Pot emissions } & \\
\hline $\begin{array}{l}\text { All } \\
0-19 \\
20-39 \\
40+\end{array}$ & $\begin{array}{l}0 \\
0.53(6) \\
0.99(25) \\
0.79(15) \\
0.52(11)\end{array}$ & $\begin{array}{l}0 \\
0.44(5) \\
0.74(9) \\
0.67(5)\end{array}$ & $\begin{array}{l}<4.3 \\
1.04(10) \\
0.93(6) \\
1.16(10) \\
1.67(13)\end{array}$ & $\begin{array}{l}\geqslant 4.3 \\
1.45(20) \\
1.68(5) \\
1.53(11) \\
2.04(12)\end{array}$ & $\begin{array}{l}0.02 \\
0.03 t \\
0.10 t \\
0.03 t\end{array}$ \\
\hline
\end{tabular}

^Employed in unexposed work at some time during time window. †Unexposed employed $v$ low cumulative exposure $v$ high cumulative exposure. Expected number in italics if SMR $=0.00$.

association for mortality from ischaemic heart disease alone $(P=0.07)$.

Cumulative exposure to pot emissions showed a weak, negative association with mortality from ischaemic heart disease $(\mathbf{P}=$ $0 \cdot 10)$ and no association with mortality from sudden death. Time window analysis did not provide any additional information (not shown in table). The presence of an acute effect was assessed through analysis by exposures at the time of observation, and included both short term workers and men employed for three years or more. This showed an SMR for ischaemic heart disease and sudden death of 0.84 (four deaths) among the currently exposed men $v 0.66$ (five deaths) among those employed in unexposed work (not shown in table).

More deaths than expected from chronic obstructive lung disease were found in men exposed to pot emissions ( $\mathrm{SMR}=1.97, \mathrm{P}<$ 0.05 ), but still the trend analysis showed no association with cumulative exposure. Time window analysis showed a weakly positive association with exposures received 20-39 years before observation $(P=0.06)$.

No trend could be detected when the increased mortality from hypertensive disease was analysed by cumulative exposure to tar or pot emissions (not shown in tables). As hypertension is the predominant risk factor for cerebrovascular disease, mortality from this cause was also included in the analysis (table 4). This led to the unexpected finding of a strong association between cumulative exposure to pot emissions and cerebrovascular mortality $(P=0.02)$. No association was seen with cumulative exposure to tar, although time window analysis showed an excess among men exposed to tar 40 years or more before observation $(\mathrm{SMR}=1 \cdot 61)$.

POISSON REGRESSION ANALYSIS

Table 5 shows results from the Poisson regression analysis of mortality from causes related to atherosclerosis and cerebrovascular disease in men employed for at least three years. Based on the results of the

Table 5 Poisson regression analysis of associations between exposure to tar and pot emissions and mortality from atherosclerotic and cerebrovascular diseases in 661 aluminium smelter workers with at least three years' employment

\begin{tabular}{|c|c|c|c|c|c|}
\hline Cause of death & Variable & Category & $\begin{array}{l}\text { Relative risk, adjusted } \\
\text { for all other variables } \\
(95 \% \mathrm{CI})\end{array}$ & $\begin{array}{l}P \text { value } \\
\text { (likelihood } \\
\text { ratio test) }\end{array}$ & $\begin{array}{l}P \text { value } \\
\text { (trend } \\
\text { test) }\end{array}$ \\
\hline $\begin{array}{l}\text { Atherosclerotic } \\
\text { diseases: }{ }^{\star}\end{array}$ & $\begin{array}{l}\text { Tar exposure } \\
(\geqslant 40 \\
\text { intensity-y) } \\
\text { Pot emission exposure } \\
\text { (intensity-y) } \\
\text { Age (y) } \\
\quad \text { Period } \\
\text { (calendar y) }\end{array}$ & $\begin{array}{l}\text { Nil } \\
<3 \\
\geqslant 3 \\
\text { Nil } \\
<4 \cdot 3 \\
\geqslant 4 \cdot 3 \\
0-64 \\
65-74 \\
\geqslant 75 \\
1962-71 \\
1972-81 \\
1982-91\end{array}$ & $\begin{array}{l}1.0 \\
1.7(0.9-3 \cdot 2) \\
1.8(1.0-3 \cdot 3) \\
1.0 \\
0.8(0.5-1 \cdot 3) \\
0.7(0.5-1 \cdot 1) \\
1.0 \\
6.5(3.8-11.0) \\
17.0(9.9-29 \cdot 2) \\
1.0 \\
1.2(0.7-2 \cdot 1) \\
0.9(0.5-1.5)\end{array}$ & $\begin{array}{r}0.09 \\
0.36 \\
0.00 \\
0.30\end{array}$ & $\begin{array}{l}0.03 \\
0 \cdot 16 \\
- \\
-\end{array}$ \\
\hline $\begin{array}{l}\text { Cerebrovascular } \\
\text { disease: }{ }^{\star}\end{array}$ & $\begin{array}{l}\text { Tar exposure } \\
(\geqslant 40 \\
\text { intensity-y) } \\
\text { Pot emission exposure } \\
\text { (intensity-y) } \\
\text { Age (y) } \\
\text { Period } \\
\text { (calendar y) }\end{array}$ & $\begin{array}{l}\text { Nil } \\
<3 \\
\geqslant 3 \\
\text { Nil } \\
<4 \cdot 3 \\
\geqslant 4 \cdot 3 \\
0-64 \\
65-74 \\
\geqslant 75 \\
1962-71 \\
1972-81 \\
1982-91\end{array}$ & $\begin{array}{l}1 \cdot 0 \\
1.9(0 \cdot 7-5 \cdot 6) \\
2 \cdot 1(0 \cdot 7-6 \cdot 3) \\
1 \cdot 0 \\
2 \cdot 1(0 \cdot 7-5 \cdot 8) \\
3 \cdot 1(1 \cdot 2-7 \cdot 9) \\
1 \cdot 0 \\
14 \cdot 9(4 \cdot 1-54 \cdot 5) \\
68 \cdot 5(19 \cdot 0-247) \\
1 \cdot 0 \\
0.5(0 \cdot 2-1 \cdot 3) \\
0.9(0 \cdot 3-1 \cdot 5)\end{array}$ & $\begin{array}{l}0.27 \\
0.04 \\
0.00 \\
0.37\end{array}$ & $\begin{array}{l}0 \cdot 10 \\
0.02 \\
-\end{array}$ \\
\hline
\end{tabular}


SMR analysis, cumulative exposure attained 40 years before observation was chosen as the exposure variable for coal tar pitch volatiles, whereas no time window restriction was enforced on the variable for pot emissions.

The risk of dying from atherosclerotic diseases was positively associated with tar exposure (trend test: $P=0.03$ ), whereas a weak negative association was found with exposure to pot emissions $(P=0 \cdot 16)$. Cerebrovascular mortality showed a significant association with exposure to pot emissions $(P=0.02)$ and a weaker association with tar exposure $(P=0 \cdot 10)$.

\section{SHORT TERM WORKERS}

Mortality from chronic obstructive lung disease in men with less than three years employment was no higher in those exposed to pot emissions ( $\mathrm{SMR}=2 \cdot 62$, seven deaths) than in unexposed workers (SMR $=4.44$, four deaths). This was also the case for cerebrovascular mortality, with an SMR of 0.60 (six deaths) in the exposed men against 1.29 (five deaths) in the unexposed men. Mortality from atherosclerotic diseases was higher in the short term workers exposed to tar (SMR = $1 \cdot 36,19$ deaths) than in unexposed workers (SMR $=0.96,37$ deaths), but no excess was seen in those with at least one intensity-year of tar exposure (SMR $=0.96$, nine deaths).

\section{Discussion}

In this study mortality from causes related to atherosclerosis was associated with cumulative exposure to tar attained 40 years before observation. A weak association was also found between exposure to pot emissions 20-39 years before observation and mortality from chronic obstructive lung disease, whereas no association could be detected between exposure to carbon monoxide and mortality from ischaemic heart disease. An unexpected finding was the association of pot emissions with cerebrovascular mortality.

The smelter was located in Aust-Agder county, and the last known address of most cohort members was in that area. Mortality among men from this county between 1981 and 1985 was $88 \%$ of the national average for ischaemic heart disease, $105 \%$ for cerebrovascular disease, and $94 \%$ for respiratory diseases. ${ }^{22}$ The choice of a local comparison population would therefore have had little effect on the SMRs, and probably no effect on the observed trends.

The accuracy of diagnoses on the death certificates used in this study was probably lower than the national average, as necropsy was performed for only $4 \%$ of all deaths in the county between 1964 and 1991 (Eivindson A, Aust-Agder Central Hospital; personal communication) compared with $10-15 \%$ in the whole country. The resulting misclassification of causes would not differentiate between exposure categories, and this could only lead to dilution of any true association in the stratified or internal analysis. More serious is the diagnostic bias that might arise if the local physicians and hospital had been aware of the risk of a particular disease in a group of smelter workers, but no such knowledge seems to have existed (Eivindson $\mathrm{A}$, Aust-Agder Central Hospital; personal communication).

Smoking is a major risk factor for the diseases of interest here, and the absence of smoking data for each worker is a weakness in this study. Data referred to in the cancer morbidity study suggest that the proportion of smokers among men employed for at least three years was only slightly higher than in Norwegian men, and the average tobacco consumption per smoker was close to the national average. ${ }^{7}$ Differences in smoking habits would be expected to be independent of specific exposures. The diseases most strongly related to smoking are lung cancer and chronic obstructive lung disease, and these showed no common pattern that might suggest the presence of excessive smoking in any particular group.

Confounding due to differences in the age or period distribution across strata seems to have been of little importance in the SMR analysis of atherosclerotic and cerebrovascular mortality as relative risks calculated from the SMRs were similar to those estimated in the Poisson regression analysis.

CHRONIC OBSTRUCTIVE LUNG DISEASE

The results for chronic obstructive lung disease support an association with exposure to pot emissions, although a non-significant trend not originally specified in a time window is not strong evidence. A previous investigation has shown increased mortality from emphysema in one group of potroom workers and asthma and chronic airways obstruction in another, ${ }^{1}$ and increased respiratory mortality has also been reported in workers from a Canadian aluminium smelter. ${ }^{2}$ Unfortunately, the use of different groupings of respiratory diseases in these studies makes it difficult to compare results.

Data referred to in the exposure assessment provide an indication of the absolute exposures possibly associated with increased mortality from this cause. Average exposures of $1.5-3.7 \mathrm{mg} / \mathrm{m}^{3}$ total fluorides and $1.8-2.9$ ppm sulphur dioxide were considered to be representative of conditions in the potrooms of the present smelter between 1955 and 1965, whereas exposure estimates before this time were $33 \%$ higher. $^{6}$

No association was found between asbestos exposure and mortality from chronic obstructive lung disease. Neither of the two deaths from pneumoconiosis in the cohort had a work history that implied exposure to asbestos or pot emissions, but both had been employed in a neighbouring ferrosilicon smelter with a recognised silicosis hazard. The proportion with employment in this factory among the deaths from chronic obstructive lung disease $(3 / 14,21 \%)$ was similar to that in the whole subcohort of men with at least three years employment (19\%). 
ATHEROSCLEROTIC DISEASES

The results of tar exposure and atherosclerotic mortality support some earlier findings from studies of workers exposed to tar in other industries. ${ }^{9-11}$ The association with cumulative exposure attained 40 years before observation is suggestive of an effect at an early stage in the disease process. It is tempting to relate this to the ability of some PAHs to stimulate the growth of atheromatous plaques, ${ }^{1213}$ which is a characteristic early event in the pathogenesis of atherosclerosis. ${ }^{14}$ Similar latency periods have been reported from studies of mortality from ischaemic heart disease in gas workers ${ }^{10}$ and chimney sweeps exposed to tar, ${ }^{11}$ but not in tar distillation workers. ${ }^{9}$

This association could be detected only through stratified analysis, whereas the SMR of 0.88 for ischaemic heart disease in men employed for at least three years compares well with results from other studies of aluminium smelter workers. ${ }^{1-3}$ Only one of these included a stratified analysis of circulatory mortality by tar exposure that showed a higher SMR for circulatory diseases in workers exposed to tar than in those unexposed. ${ }^{2}$ Most potrooms in this plant were of the Søderberg type with high tar exposures, and a casecontrol study of ischaemic heart disease in the same workforce between 1975 and 1983 showed a significantly increased risk in potroom workers. ${ }^{5}$ After adjustment for hypertension, hyperglycaemia, and hypercholesterolaemia this study showed no association with tar or other exposures, but one might speculate that such adjustment could have accounted for the effect of exposure if exerted through one of these personal risk factors.

The present data showed no association between cumulative or current exposure to pot emissions and mortality from ischaemic heart disease. This exposure included average carbon monoxide concentrations of $40-80$ ppm, ${ }^{6}$ and similar concentrations have been implicated as a potential cause of ischaemic heart disease in road tunnel workers, ${ }^{8}$ but this received no support from the results presented here.

Night work has also been associated with increased morbidity from ischaemic heart disease, ${ }^{23}$ but in the cohort studied here such work schedules were common only among those exposed to pot emissions, who showed a lower than expected mortality from this cause.

\section{CEREBROVASCULAR DISEASE}

The Poisson regression analysis is suggestive of an association between cumulative exposure to $\operatorname{tar} 40$ years before observation and cerebrovascular mortality. This is not totally surprising as atherosclerosis is a risk factor for cerebral thrombosis, an important type of cerebrovascular disease. ${ }^{14}$ The association with exposure to pot emissions was unexpected, and the finding of this association in all three time windows is suggestive of a persistent effect.

Hypertension is the predominant risk factor for cerebrovascular disease, and one might speculate that some constituent of pot emissions or a correlated agent could have an effect on blood pressure. A previous Norwegian study showed no association between potroom work and blood pressure in workers aged $20-49,24$ but this may not necessarily be relevant to those at risk of cerebrovascular disease, the mean (SD) age at death being 77 (8) years in the present cohort. Exposure to pot emissions was strongly correlated to exposure to heat stress, ${ }^{6}$ and there is some evidence that heat stress can lead to increased blood pressure. ${ }^{25}$ Increased blood pressure has also been reported in workers threatened by unemployment, ${ }^{26}$ and one might speculate that the decision to close the smelter taken in 1972 could have contributed to increased blood pressure, but the Poisson regression analysis showed a higher relative risk of dying from cerebrovascular disease between 1962 and 1971 than after 1972 .

\section{SHORT TERM WORKERS}

Whereas total mortality was slightly lower than expected in men with at least three years employment, those with shorter employment showed a significant increase in both total mortality and total cancer incidence. ${ }^{7}$ Still, none of the associations between specific exposures and causes of death or cancers found in the longer term subcohort seemed to be present among the short term workers. The excess of cases of lung cancer and increased mortality from chronic obstructive lung disease and peripheral arteriosclerosis may suggest that excessive smoking has been an important contributory factor, possibly together with other lifestyle factors and employment in many unhealthy workplaces.

Oddvar Sandvin designed all programs used with the "epicure" software, and Tor Haldorsen contributed to the statistical analysis. I am also grateful to Aage Andersen and Eystein Glattre for comments on the manuscript. This work was supported by grants from The Nordic Aluminium Industry's Secretariat for Health, Environment and Safety (AMS) and from the Work Environment Fund of the Confederation of Norwegian Business and Industry (NHO).

1 Rockette HE, Arena VC. Mortality studies of aluminium reduction plant workers: potroom and carbon department. F Occup Med 1983;25:549-57.

2 Gibbs GW. Mortality of aluminium reduction plant workers, 1950 through 1977. F Occup Med 1985;27:761-70.

3 Spinelli JJ, Band PR, Svirchev L, Gallagher RP. Mortality and cancer incidence in aluminium reduction plant workers. $₹$ Occup Med 1991;33:1150-5.

4 Abramson MJ, Wlodarczyk JH, Saunders NA, Hensley MJ. Does aluminium smelting cause lung disease? $A m$ Rev Respir Dis 1989;139:1042-57.

5 Thériault GP, Tremblay CG, Armstrong BG. Risk of ischemic heart disease among primary aluminium production workers. Am $\mathcal{F}$ Ind Med 1988;13:659-66.

$6 \mathrm{R} \phi$ nneberg A. Mortality and cancer morbidity in workers from an aluminium smelter with prebaked carbon anodes. Part I: exposure assessment. Occup Environ Med 1995;52:242-9.

7 Rønneberg A, Andersen A. Mortality and cancer morbidity in workers from an aluminium smelter with prebaked carbon anodes. Part II: cancer morbidity. Occup Environ Med 1995;52:250-4.

8 Stern FB, Halperin WE, Hornung RW, Ringenburg VL, McCammon CS. Heart disease mortality among bridge and tunnel officers exposed to carbon monoxide. Epidemiol 1988;128:1276-88.

9 Maclaren WM, Hurley JF. Mortality of tar distillation workers. Scand $\mathcal{f}$ Work Environ Health 1987;13:404-11.

10 Gustavsson P, Reuterwall C. Mortality and incidence of cancer among Swedish gas workers. Br f Ind Med 1990; cancer amo

11 Evanoff BA, Gustavsson P, Hogstedt C. Mortality and 
incidence of cancer in a cohort of Swedish chimney sweeps: an extended follow up study. $\mathrm{Br} F$ Ind Med 1993; 50:450-9.

12 Bond JA, Gown AM, Yang HL, Benditt EP, Juchau MR Further investigations of the capacity of polynuclear aromatic hydrocarbons to elicit atherosclerotic lesions. f Toxicol Environ Health 1981;7:327-35.

13 Penn A, Snyder C. Arteriosclerotic plaque development is promoted by polynuclear aromatic hydrocarbons. Carcinogenesis 1988;9:2185-9.

14 US Department of Health and Human Services. The health consequences of smoking: cardiovascular disease. Rockville, Maryland: Public Health Service, Office on Smoking and Health, 1983.

15 Central Bureau of Statistics (CBS). Causes of death 1991. Oslo, Norway: CBS, 1993, 10-1.

16 Kristensen TS. Cardiovascular diseases and the work environment: a critical review of the epidemiologic literature ronment: a critical review of the epidemiologic literature on chemical facto

17 Breslow NE, Day NE. Statistical methods in cancer research. Vol II-The design and analysis of cohort studies. Lyon, France: International Agency for Research on Cancer, 1987:96-7.

18 Breslow NE, Day NE. Statistical methods in cancer research. Vol II-The design and analysis of cohort studies. Lyon, France: International Agency for Research on Cancer, 1987:120-50.
19 Breslow NE, Day NE. Statistical methods in cancer research. Vol I-The analysis of case-control studies. Lyon, France: International Agency for Research on Cancer, 1980.

20 Clayton D, Hills M. Statistical models in epidemiology. Oxford: Oxford University Press, 1993, chapters 20 and

21 Preston DL, Lubin JH, Pierce DA, McConney ME. Epicure. Seattle, Washington: Hirosoft International Corporation, 1993

22 Central Bureau of Statistics (CBS). Regional Mortality 1981-85. Oslo, Norway: CBS, 1988.

23 Tüchsen F. Working hours and ischaemic heart disease in Danish men: a 4-year cohort study of hospitalization. Int f Epidemiol 1993;22:215-21.

24 Lund-Larsen P, Dahlberg BE. Blood pressure in aluminium plant workers employed in high and in normal minium plant workers employed in high and in normal Tidsskr Nor Lagefor 1981;101:1892-5.

25 Kristensen TS. Cardiovascular diseases and the work environment: a critical review of the epidemiologic literature on nonchemical factors. Scand $\mathcal{f}$ Work Environ Health 1989;15:165-79.

26 Erikssen J, Knudsen K, Mowinckel P, Guthe T, Lützow Holm JP, Brandtzæg R, Rodahl K. Blood pressure increase in an industrial population exposed to longterm stress. Tidsskr Nor Lagefor 1990;110:2873-7. (In Norwegian.)

\section{Rejected manuscripts}

From February 1994, authors whose submitted articles are rejected will be advised of the decision and one copy of the article, together with any reviewers' comments, will be returned to them. The fournal will destroy remaining copies of the article but correspondence and reviewers' comments will be kept. 